\title{
Ordered Mesoporous Carbons as Novel and Efficient Adsorbent for Dye Removal from Aqueous Solution
}

\author{
Phuong T. Dang, Hoa T. H. Nguyen, Canh D. Dao, Giang H. Le, Quang K. Nguyen, \\ Kien T. Nguyen, Hoa T. K. Tran, Tuyen V. Nguyen, and Tuan A. Vu \\ Department of Surface Chemistry, Institute of Chemistry, Vietnam Academy of Science and Technology (VAST), \\ 18 Hoang Quoc Viet, Cau Giay District, Hanoi, Vietnam
}

Correspondence should be addressed to Tuan A. Vu; vuanhtuan.vast@gmail.com

Received 17 February 2016; Accepted 20 July 2016

Academic Editor: Somchai Thongtem

Copyright (C) 2016 Phuong T. Dang et al. This is an open access article distributed under the Creative Commons Attribution License, which permits unrestricted use, distribution, and reproduction in any medium, provided the original work is properly cited.

Ordered mesoporous carbons (OMCs) were successfully synthesized by using hard template and soft template methods. These materials were characterized by XRD, TEM, and $\mathrm{N}_{2}$ adsorption-desorption Brunauer-Emmett-Teller (BET). From the obtained results, it is revealed that the obtained OMCs samples showed high surface area $\left(>1000 \mathrm{~m}^{2} / \mathrm{g}\right)$ with high pore volume, mainly mesopore volume $\left(1.2-2.4 \mathrm{~cm}^{3} / \mathrm{g}\right)$. Moreover, OMCs samples had similar structure of the SBA-15 silica and exhibited high MB adsorption capacity with $q_{m}$ of $398 \mathrm{mg} \cdot \mathrm{g}^{-1}$ for OMCs synthesis with hard template and $476 \mathrm{mg} \cdot \mathrm{g}^{-1}$ for OMCs synthesis with soft template, respectively. From kinetics investigation, it is confirmed that MB adsorption from aqueous solution obeys the pseudosecond-order kinetic equation.

\section{Introduction}

In recent years, the synthesis of porous carbon materials with ordered mesopore array owing to their unique characteristics including highly periodic pore arrangement, uniform nanosize, high surface area, and large pore volume has received a great interest of researchers. Porous carbons [1-3] are widely used in many applications such as gas storage $[4,5]$, gas separation [6], catalysis [7, 8], electrochemical energy storage [9], and adsorption [10-12]. These materials showed high specific surface area with the contributions of both micropores and mesopores. Among porous carbon materials, carbon nanotubes have been intensively investigated. However, synthesis of carbon nanotubes with mesopores raised problems such as purity of products (removal catalyst) and mixture structure (single and multiwalls) $[13,14]$. Ghaedi et al. [13] compared the efficiency of activated carbon (AC) and multiwalled carbon nanotube (MWCNT) for the removal of Eriochrome Cyanine R (ECR) molecules from aqueous solutions. They claimed that the sorption processes followed the pseudosecond-order in addition to intraparticle diffusion kinetics models with a good correlation coefficient with the overall entire adsorption of ECR on both adsorbents. Equilibrium data fit well with the Langmuir and Temkin models with a maximum sorption capacity based on the Langmuir equation of 40.6 and $95.2 \mathrm{mg} / \mathrm{g}$ for AC and MWCNT, respectively. Ordered mesoporous carbons (OMCs) are still rarely explored as adsorbent for dye removal. Ordered mesoporous carbons are mainly synthesized by the hard template method using ordered mesoporous silica like Si-MCM-41 and SiSBA-15 as stating material and following the carbonization process [15]. Recently, a few papers described the preparation of OMCs using soft template methods [15-17]. Libbrecht et al. [15] reported the mesoporous carbons synthesized by both soft and hard template methods and compared them to a commercial powder activated carbon (PAC) for the adsorption ability of bisphenol-A (BPA) from an aqueous solution. The maximum observed adsorption capacity $\left(q_{m}\right)$ of CMK-3 was the highest with $474 \mathrm{mg} \cdot \mathrm{g}^{-1}$, compared to that of $290 \mathrm{mg} \cdot \mathrm{g}^{-1}$ for PAC and $154 \mathrm{mg} \cdot \mathrm{g}^{-1}$ for SMC. The difference in adsorption capacities was attributed to the specific surface area and hydrophobicity of the adsorbents.

In the case of soft template method, the advantage is that the template contained in ordered mesoporous silica can be 

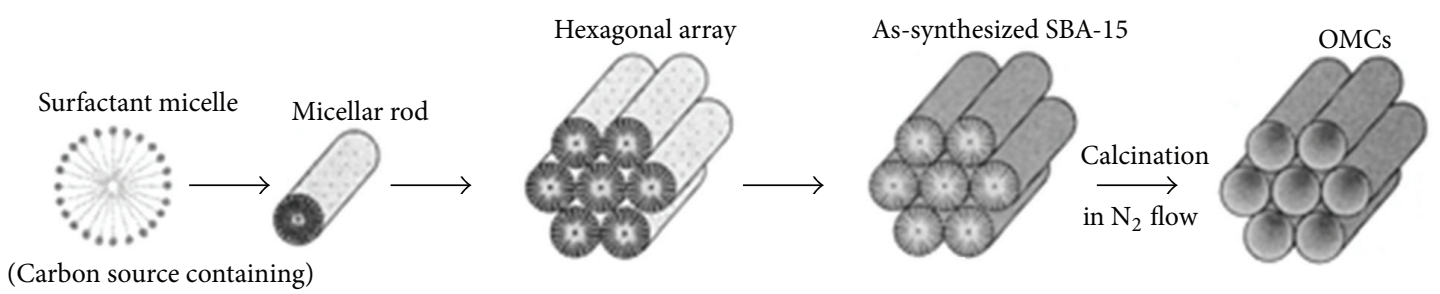

SCHEME 1

directly used as carbon source. Scheme of OMCs synthesis by the soft template is described as in Scheme 1.

In this paper, we report the synthesis of OMCs using both hard template and soft template method and their application as highly efficient adsorbents for methylene blue (MB) removal from aqueous solution. The effects of $\mathrm{pH}$, $\mathrm{MB}$, and OMCs concentration and the influence of OMCs pore structures as well as kinetics of MB over these OMCs materials were investigated.

\section{Experimental}

2.1. OMC-H Preparation. SBA-15 silica following synthesis procedure was reported by Nie et al. [26]. OMCs were synthesized by calcinations of SBA-15 impregnated with aqueous solution of carbon sources with sulfuric acid. Typically, $2 \mathrm{~g}$ of sucrose was mixed with $1 \mathrm{~g}$ SBA-15 and then added to a solution obtained by dissolving $0.14 \mathrm{~g}$ of $\mathrm{H}_{2} \mathrm{SO}_{4}$ in $5 \mathrm{~g}$ of $\mathrm{H}_{2} \mathrm{O}$. The mixture was placed in a drying oven for $6 \mathrm{~h}$ at $100^{\circ} \mathrm{C}$, and subsequently the oven temperature was increased to $160^{\circ} \mathrm{C}$ and maintained there for $6 \mathrm{~h}$. The sample turned dark brown or black during the treatment in the oven. We repeated this step at 100 and $160^{\circ} \mathrm{C}$ using the same oven after the addition of $1 \mathrm{~g}$ of carbon, $0.14 \mathrm{~g}$ of $\mathrm{H}_{2} \mathrm{SO}_{4}$, and $5 \mathrm{~g}$ of $\mathrm{H}_{2} \mathrm{O}$. The carbonization was completed by pyrolysis with heating at typically $900^{\circ} \mathrm{C}$ under nitrogen flow. The carbonsilica composite obtained after pyrolysis was immerged in $\mathrm{HF} 40 \%$ solution and then washed with $\mathrm{H}_{2} \mathrm{O}$ before being washed with mixture of $50 \mathrm{vol} \%$ ethanol +50 vol $\% \mathrm{H}_{2} \mathrm{O}$. Final product was dried at $100^{\circ} \mathrm{C}$ for $3 \mathrm{~h}$.

2.2. OMCs-S Preparation. OMCs-S was synthesized as follows: $3 \mathrm{~g}$ of F127 dissolved in $30 \mathrm{~g}$ ethanol and then to this mixture $\mathrm{HCl} 0.2 \mathrm{M}$ solution was added and stirred at $40^{\circ} \mathrm{C}$ for $1 \mathrm{~h}$. Next, $3.9 \mathrm{~g}$ of tetraethyl orthosilicate (TEOS) and resols solution ( $25 \% \mathrm{wt}$ ) with molar ratio resol/F127 by 0.85 is added and the mixture is kept stirring for $2 \mathrm{~h}$, at $40^{\circ} \mathrm{C}$. After 2 hours of stirring at $40^{\circ} \mathrm{C}$, the obtained clear solution is poured out to disk for ethanol evaporation at room temperature for $24 \mathrm{~h}$. Thin film was obtained by dried sample at $120^{\circ} \mathrm{C}$ for polymerization in 24 . This thin film is heated in $\mathrm{N}_{2}$ flow from room temperature to $350^{\circ} \mathrm{C}$ in $1 \mathrm{~h}$, then continued to raise the calcinations temperature up to $700^{\circ} \mathrm{C}$, and keeps at this temperature in $2 \mathrm{~h}$ (carbonization). The obtained sample was washed in $\mathrm{HF} 10 \%$ solution and dried at $50^{\circ} \mathrm{C}$ for $4 \mathrm{~h}$. Finally, sample was washed with $\mathrm{H}_{2} \mathrm{O}$ before being washed with ethanol-water mixture with a volume ratio of $50: 50$ before being dried at $80^{\circ} \mathrm{C}$ in $3 \mathrm{~h}$.
2.3. Characterization. The powder X-ray diffraction (XRD) patterns of the samples were recorded on a Shimadzu XRD6100 analyzer with $\mathrm{Cu} \mathrm{K}_{\alpha}$ radiation $(l=1.5417 \AA)$. Transmission electron microscopy (TEM) was recorded using JEOL 1010 instrument operating at $80 \mathrm{kV}$ with magnification of 25,000-100,000. Surface area of samples was determined on Quantachrome Instruments version 3.0 at $77 \mathrm{~K}$ and using nitrogen adsorbent. $\mathrm{pH}$ was investigated using microprocessor $\mathrm{pH} /$ Ion Meter pMX3000 (Germany) (scale \pm 0.03 ).

2.4. Adsorption Experiments. The methylene blue $\left(\mathrm{C}_{16} \mathrm{H}_{18} \mathrm{~N}_{3} \mathrm{SCl}\right.$, 95\% of purity) was purchased from Merck (Germany). MB adsorption was performed in liquid phase at room temperature under stirring condition. Batch experiments were carried out in a set of $250 \mathrm{~mL}$ Erlenmeyer flasks, in which a $100 \mathrm{~mL}$ aliquot of each $\mathrm{MB}$ solution with initial concentrations in the range of $100-300 \mathrm{ppm}$ was added. Equal masses $(W)$ of $0.05 \mathrm{~g}$ adsorbent were added to the $\mathrm{MB}$ solutions $(V)$. The $\mathrm{pH}$ values of the solutions were adjusted using $\mathrm{HCl} 0.1 \mathrm{M}$ or $\mathrm{NaOH} 0.1 \mathrm{M}$. Removal efficiency $(\mathrm{H} \%)$ of $\mathrm{MB}$ is defined as follows:

$$
H(\%)=\frac{C_{o}-C_{e}}{C_{o}} \times 100 \%,
$$

where $C_{o}$ and $C_{e}(\mathrm{ppm})$ are initial and equal MB concentration.

\section{Results and Discussion}

3.1. X-Ray Diffraction (XRD). XRD patterns of OMCs and SBA-15 samples are shown in Figure 1. XRD pattern of SBA-15 showed three sharp peaks which are assigned to the (100), (110), and (200) reflections, characteristic of the $2 \mathrm{D}$ hexagonal space group $\mathrm{p} 6 \mathrm{~mm}$. In the case of OMCs-H sample, only an intense peak at $2 \theta$ of $1.2^{\circ}$ assigned to (100) reflection was observed. This result confirmed that OMCs$\mathrm{H}$ had the same structure of SBA-15 but not well-ordered structure as compared to that of SBA-15. Similarly, the XRD pattern of OMCs-S showed an intense peak at $2 \theta$ of $1.2^{\circ}$ but the intensity of this peak is much lower, indicating the less ordered structure of this material.

3.2. Transmission Electron Microscopy (TEM). The TEM images in Figure 2 show that SBA-15 and OMCs-H have the same morphology. These results confirm that the synthesis method of OMCs-H does not change the SBA-15 structure. However, the pores of SBA-15 are uniform with diameters 


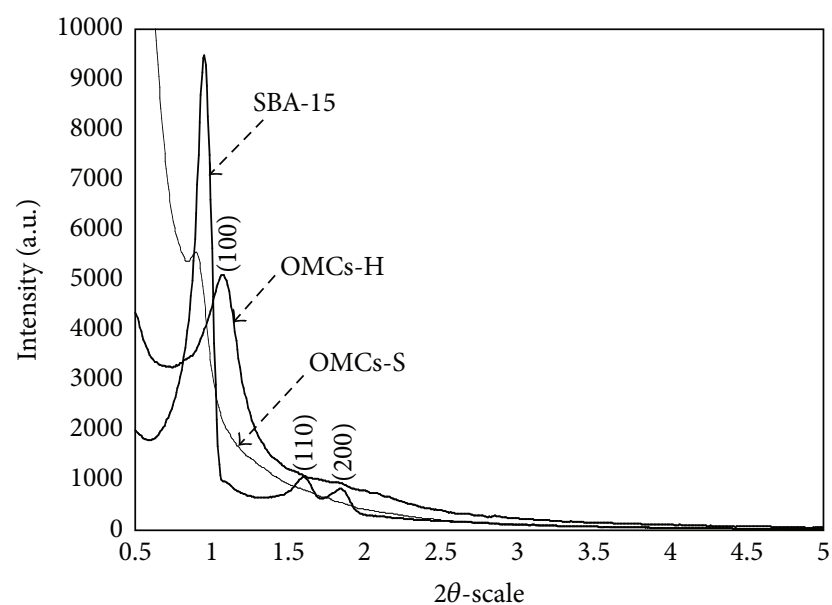

Figure 1: XRD patterns of SBA-15, OMCs-H, and OMCs-S.

of approximately 6-7 $\mathrm{nm}$, larger than those of OMCs-H (4$5 \mathrm{~nm}$ ); this can explain that OMCs-H was formed inside the SBA-15 pores walls narrowing the pore size. In contrast, OMCs-S was formed from direct structure template (copolymer F127), located within the pores of Si-SBA-15; therefore it is difficult to control the distribution and size of the pores.

3.3. $\mathrm{N}_{2}$ Adsorption-Desorption (BET) Isotherms. $\mathrm{N}_{2}$ adsorption-desorption isotherms and pore-sized distribution of OMCs-H and OMCs-S are presented in Figure 3. As observed in Figure 3, both OMCs showed the isotherm curves of type IV with the hysteresis loop, characteristic for capillary condensation which is often noted for mesoporous material. Textural characteristics of samples are given in Table 1. As observed in Table 1, both OMCs-H and OMCs-S showed higher surface area as compared to that of SBA-15. Thus, surface area of OMCs-S is $1693 \mathrm{~m}^{2} / \mathrm{g}$ which is much higher than OMCs-H $\left(1041 \mathrm{~m}^{2} / \mathrm{g}\right)$ and SBA-15 $\left(650 \mathrm{~m}^{2} / \mathrm{g}\right)$. Pore size of OMCs-H is narrow distributed with the size of $4-5 \mathrm{~nm}$ while pore size of OMCs-S is also narrow distributed but with larger size, ranging from 5 to $10 \mathrm{~nm}$. Moreover, from Table 1 , it is noted that both OMCs exhibited very high pore volumes of $1.2-2.3 \mathrm{~cm}^{3} / \mathrm{g}$ which are much higher than that reported for ordered mesoporous materials [15]. Interestingly, in the case of OMCs-S synthesis by using soft template method, the new mesopores during carbonization are created. This can be rationalized by the fact that, during decomposition of copolymer F127 (copolymer of ethylene oxide and propylene oxide) in the inert gas flow, $\mathrm{H}_{2} \mathrm{O}$ formation plays the role of steaming activation to develop the new pore systems as observed on the active carbon activated by steaming [27, 28].

3.4. Effect of $p H$. It is well known that the adsorption capacity of dyes is dominated by surface area and the interaction between the adsorbate molecules and the adsorbent surface through the electrostatic attraction. The charge of adsorbent surface depends on $\mathrm{pH}$ point of zero charge $\left(\mathrm{pH}_{\mathrm{pzc}}\right)$. Figure 4 plotted the surface charge as a function of $\mathrm{pH}$ value for OMCs-S and OMCs-H. Methylene blue is a cationic dye, when $\mathrm{pH}<\mathrm{pH}_{\mathrm{pzc}}$, surface of the adsorbent positively charged, due to the expulsive force $\mathrm{MB}$ adsorption capacity decreased. In contrast, when $\mathrm{pH}>\mathrm{pH}_{\mathrm{pzc}}$ the adsorbent surface negatively charged due to the attraction force $\mathrm{MB}$ adsorption capacity increased. Moreover, at low $\mathrm{pH}$ (strong acidic medium) or high $\mathrm{pH}$ (high alkaline medium), the cations are rejected due to the affinity being weaker as compared to the proton and hydroxyl group affinity. From Figure 4, $\mathrm{pH}_{\mathrm{pzc}}$ of OMCs-S and OMCs-H is 6.0 and 5.5, respectively. The effect of $\mathrm{pH}$ solution on the adsorption equilibrium of OMCs-S and OMCs-H is shown in Figure 5. As noted in Figure 5, at $\mathrm{pH}$ of 8 (alkaline medium), MB adsorption efficiency reached the value of $98 \%$ and $95 \%$ for OMCs-S and OMCs-H, respectively. At $\mathrm{pH}$ of 7 (neutral medium), the efficiency also reached high value of $95 \%$ for OMCs-S and $93 \%$ for OMCs-H. At pH of 4 the efficiency decreased considerably (87\% for OMCs-S and $70 \%$ for OMCs-H). In the MB adsorption process, all experiments were carried out at $\mathrm{pH}$ of 7 because of high $\mathrm{MB}$ removal efficiency and the appropriate application practice.

3.5. Methylene Blue Adsorption. MB adsorption capacities at different concentrations on OMCs-H (a) and OMCs-S (b) are presented in Figure 6 and Langmuir and Freundlich isotherm constants of OMCs-H and OMCs-S are given in Table 2. From Table 2 and Figure 6, both OMCs-H and OMCs-S showed high MB adsorption capacities. However, higher adsorption capacities over OMCs-S $\left(q_{m}\right.$ of $\left.476 \mathrm{mg} \cdot \mathrm{g}^{-1}\right)$ as compared to that of OMCs-H $\left(q_{m}\right.$ of $\left.398 \mathrm{mg} / \mathrm{g}\right)$ were observed. This can be explained by the fact that OMCs-S had higher surface area $\left(1693 \mathrm{~m}^{2} / \mathrm{g}\right)$ as compared to that of OMCs$\mathrm{H}\left(1041 \mathrm{~m}^{2} / \mathrm{g}\right)$. Note that both OMCs samples exhibited much higher $\mathrm{MB}$ adsorption capacities as compared to those of the same materials (OMCs) or related materials which have been reported in the literature. Thus, Yuan et al. [18] investigated $\mathrm{MB}$ adsorption ability on OMCs and obtained only the MB maximum adsorption capacity $\left(q_{m}\right)$ of $200 \mathrm{mg} \cdot \mathrm{g}^{-1}$. Moreover, in comparison to other related materials like activated carbon and carbon nanotubes, MB adsorption capacity of OMCs synthesized in our laboratory also showed higher value (see Table 2).

3.6. Langmuir and Freundlich Isotherm Models. Two experiment equations, Langmuir and Freundlich isotherms models, were often used to analyze the experimental data $[29,30]$.

The Langmuir equation is expressed as follows:

$$
\frac{C_{e}}{q_{e}}=\frac{1}{q_{m} K_{L}}+\left(\frac{1}{q_{m}}\right) C_{e} .
$$

The Freundlich equation is expressed as follows:

$$
\log q_{e}=\log K_{F}+\left(\frac{1}{n}\right) \log C_{e},
$$

where $q_{m}$ and $K_{L}$ in the Langmuir equation represent the maximum adsorption capacity of adsorbents $\left(\mathrm{mg}^{-\mathrm{g}^{-1}}\right)$ and Langmuir adsorption constant related to the free energy of adsorption, respectively. $K_{F}$ and $n$ are Freundlich constants 


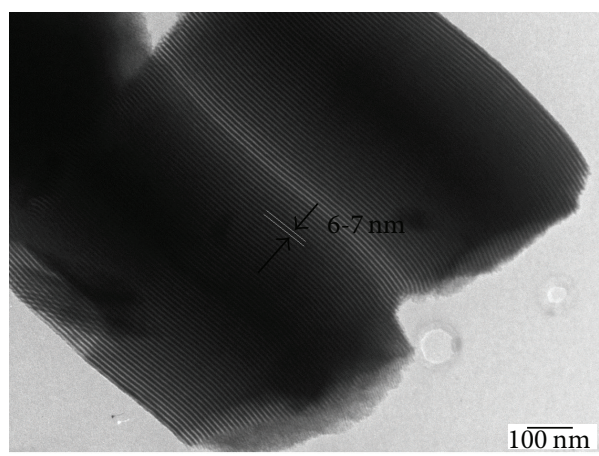

(a)

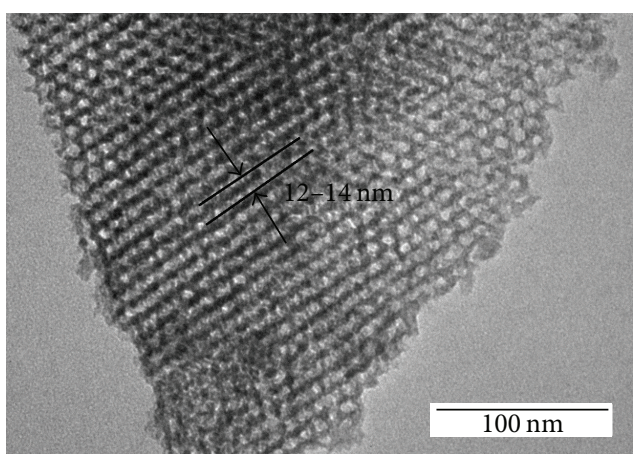

(b)

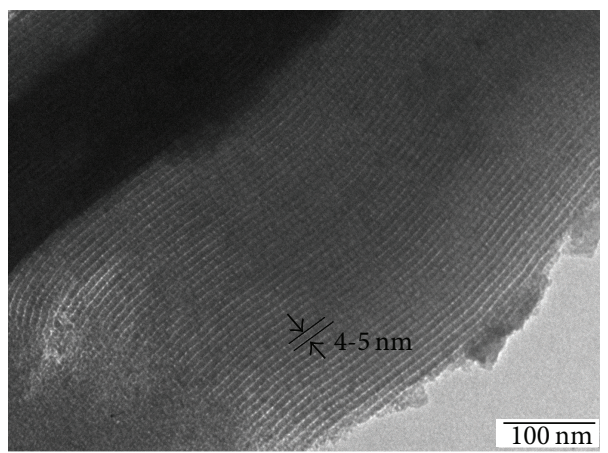

(c)

FIgure 2: TEM images of SBA-15 (a), OMCs-S (b), and OMCs-H (c).

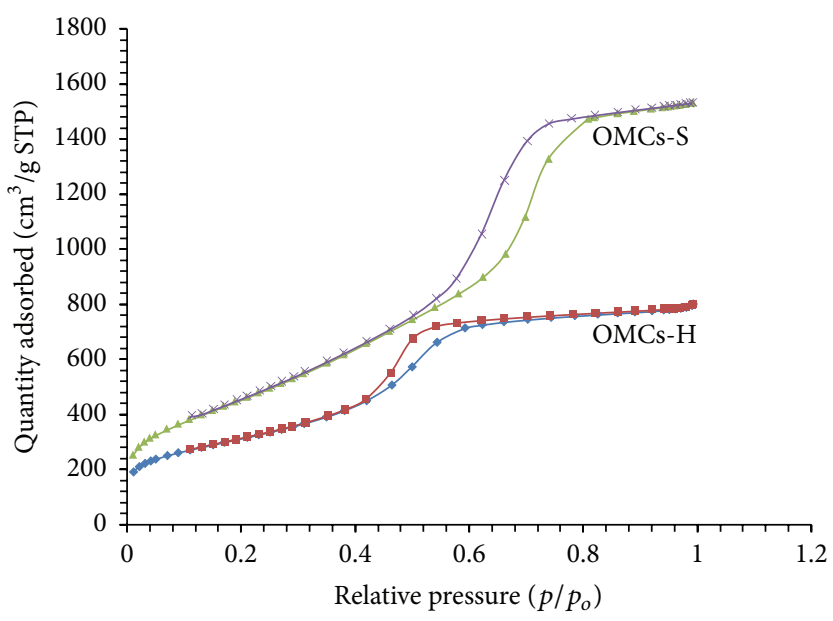

(a)

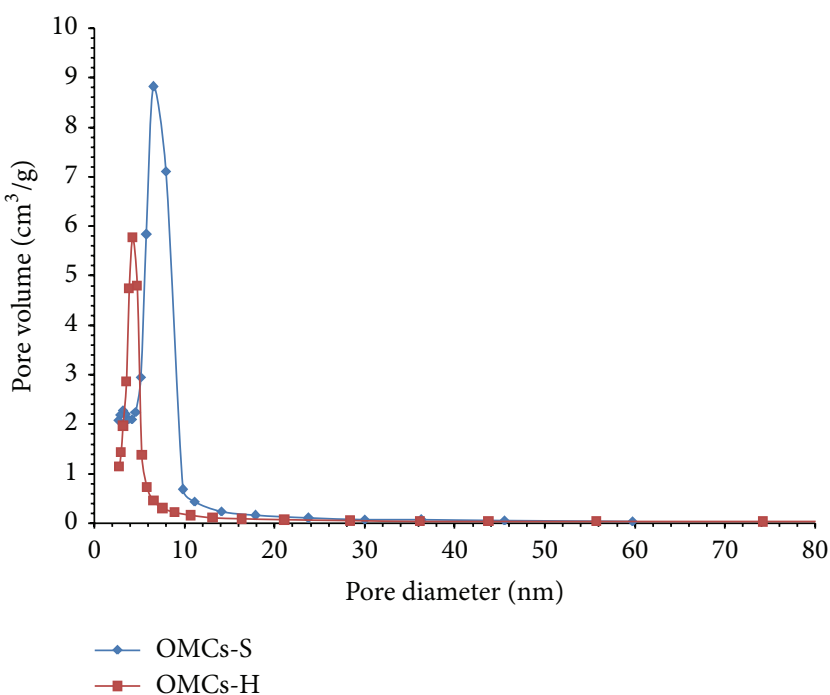

(b)

FIgURE 3: $\mathrm{N}_{2}$ adsorption-desorption isotherms (a) and pore-size distribution (b) of OMCs-H and OMCs-S.

TABLE 1: Textural properties of samples.

\begin{tabular}{lccccc}
\hline \multirow{2}{*}{ Samples } & & \multicolumn{2}{c}{ Textural properties } & \multicolumn{2}{c}{ Surface area $\left(\mathrm{m}^{2} / \mathrm{g}\right)$} \\
& Pore diameter $(\mathrm{nm})$ & Pore volume $\left(\mathrm{cm}^{3} / \mathrm{g}\right)$ & Micropore volume $\left(\mathrm{cm}^{3} / \mathrm{g}\right)$ & Mesopore volume $\left(\mathrm{cm}^{3} / \mathrm{g}\right)$ & 6.787 \\
SBA-15 & $6-7$ & 1.134 & 0.3471 & 0.875 & 1041 \\
OMCs-H & $4-5$ & 1.237 & 0.3615 & 2.253 & 1693 \\
OMCs-S & $5-10$ & 2.374 & 0.1205 & 205 & \\
\hline
\end{tabular}


TABLE 2: Comparison of MB adsorption capacity for different adsorbents.

\begin{tabular}{|c|c|c|c|c|}
\hline Adsorbent & Template & $q_{m}(\mathrm{mg} / \mathrm{g})$ & Adsorbate & References \\
\hline CFY & $\mathrm{NaY}$ & 80 & \multirow{4}{*}{ Methylene blue (MB) } & \multirow{4}{*}[18]{} \\
\hline OMC-40 & SBA-15 & 200 & & \\
\hline OMC-70 & SBA-15 & 200 & & \\
\hline OMC-100 & SBA-15 & 196 & & \\
\hline Fe-CMK-3 & SBA-15 & 316 & Methylene blue (MB) & {$[19]$} \\
\hline MCSG60 & Silica gel & 200 & Methylene blue (MB) & {$[20]$} \\
\hline Graphene/c-MWCNT & - & 191 & Methylene blue (MB) & {$[21]$} \\
\hline Date stone based AC & - & 316 & Methylene blue (MB) & {$[22]$} \\
\hline $\begin{array}{l}\text { Activated carbon produced from } \\
\text { Venezuelan bituminous coal }\end{array}$ & - & 380 & Methylene blue (MB) & {$[23]$} \\
\hline Activated sludge biomass & - & 256 & Methylene blue (MB) & {$[24]$} \\
\hline Rice husk & - & 312 & Methylene blue (MB) & {$[25]$} \\
\hline OMCs-S & - & 476 & \multirow{2}{*}{ Methylene blue (MB) } & \multirow{2}{*}{ This study } \\
\hline OMCs-H & $S B A-15$ & 398 & & \\
\hline
\end{tabular}

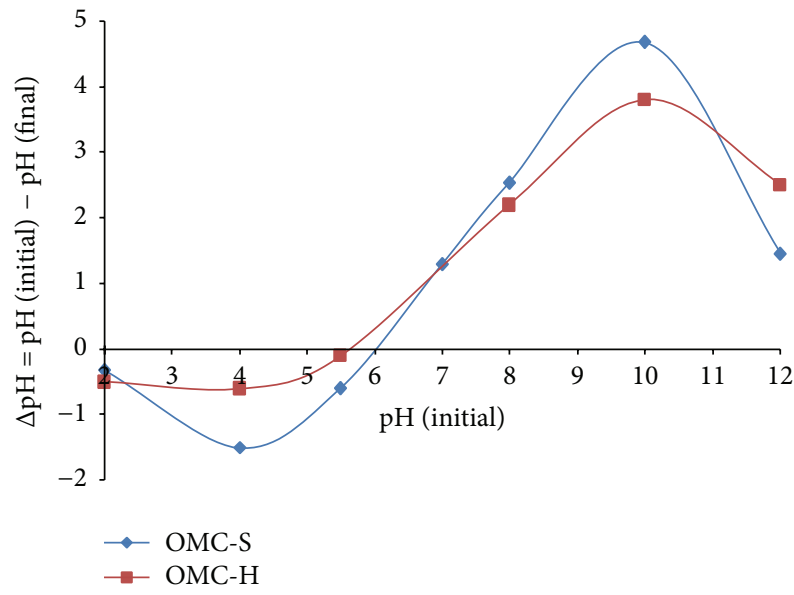

FIgUre 4: $\mathrm{pH}_{\mathrm{pzc}}$ plot of OMC-S and OMC-H.

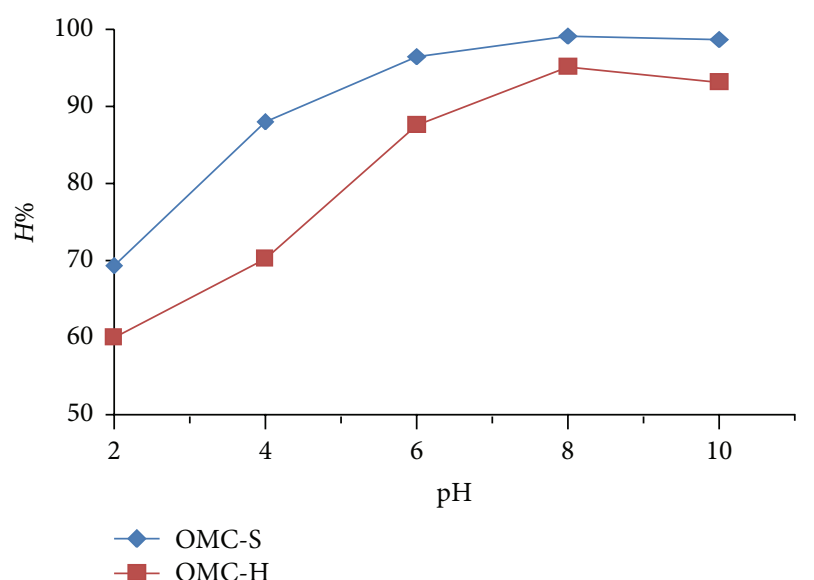

FIGURE 5: Effect of $\mathrm{pH}$ solution on the adsorption equilibrium of OMC-S and OMC-H at $[\mathrm{MB}]=200 \mathrm{ppm}, W / \mathrm{V}=0.5 \mathrm{~g} / \mathrm{L}$, and $T=$ $298 \mathrm{~K}$.
TABLE 3: Langmuir and Freundlich isotherm constants of OMCs-H and OMCs-S.

\begin{tabular}{lccc}
\hline \multicolumn{2}{c}{ Langmuir isotherm } & \multicolumn{2}{c}{ Freundlich isotherm } \\
\hline \multicolumn{3}{c}{ OMCs-H } \\
$q_{m}\left(\mathrm{mg} \cdot \mathrm{g}^{-1}\right)$ & 398 & $1 / n$ & 0.097 \\
$K_{L}\left(\mathrm{~L} \cdot \mathrm{mg}^{-1}\right)$ & 2.51 & $K_{F}\left[\left(\mathrm{mgg}^{-1}\right)\left(\mathrm{mg}^{-1}\right)^{1 / n}\right]$ & 283.59 \\
$R^{2}$ & 0.9999 & $R^{2}$ & 0.674 \\
\hline \multicolumn{3}{c}{ OMCs-S } \\
$q_{m}\left(\mathrm{mg} \cdot \mathrm{g}^{-1}\right)$ & 476 & $1 / n$ & 0.143 \\
$K_{L}\left(\mathrm{~L} \cdot \mathrm{mg}^{-1}\right)$ & 5.25 & $K_{F}\left[\left(\mathrm{mgg}^{-1}\right)\left(\mathrm{mg}^{-1}\right)^{1 / n}\right]$ & 265.44 \\
$R^{2}$ & 0.9999 & $R^{2}$ & 0.495 \\
\hline
\end{tabular}

related to adsorption capacity and adsorption intensity, respectively. The parameters of the Langmuir and Freundlich models were presented in Figure 7 and Table 3.

The Langmuir isotherm models for the adsorption of $\mathrm{MB}$ on OMCs-H and OMCs-S are presented in Figure 7. From Figure 7, it can be confirmed that the MB adsorption data on OMC-H and OMC-S fit well with Langmuir isotherm model.

As observed in Table 3, the value of $R^{2}=0.9999$ for Langmuir model with both of samples is higher than that of $R^{2}=0.674$ and 0.495 for Freundlich model with OMCs$\mathrm{H}$ and OMCs-S, respectively. This was indicating that the Langmuir model fits much better than the Freundlich model for both samples.

It is well accepted that the Langmuir isotherm assumes a surface with homogeneous binding sites, whereas the Freundlich isotherm is based on an exponential distribution of adsorption sites and adsorption onto heterogeneous surfaces. Moreover, $R_{L}$ values are too small (Table 4 ), so we can confirm that $\mathrm{MB}$ adsorption process on OMCs samples is mainly monolayer adsorption process. 


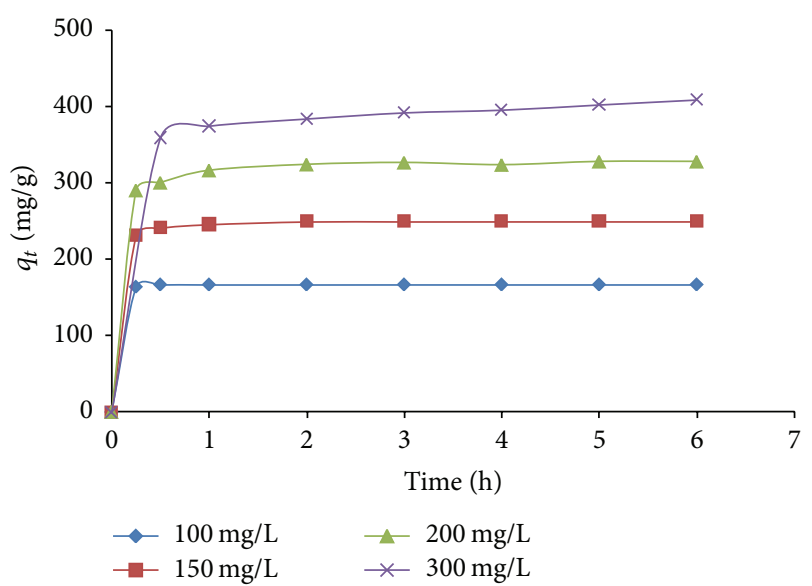

(a)

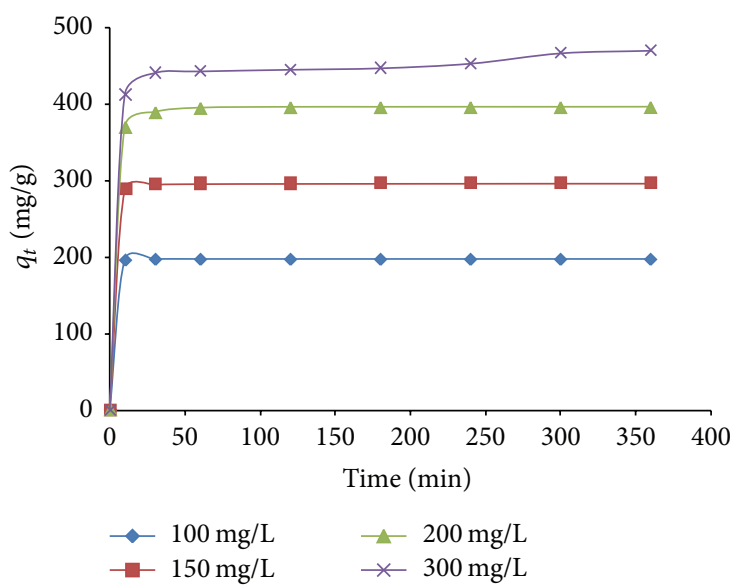

(b)

FIGURE 6: Comparison of MB adsorption capacity at different concentrations of OMCs-H (a) and OMCs-S (b).

TABLE 4: $R_{L}$ equilibrium parameter value with MB adsorption on OMCs-S and OMCs-H.

\begin{tabular}{lcccccc}
\hline$C_{o}$ (mg/L) & 100 & 150 & 200 & 300 & 400 & 500 \\
$R_{L}$ (OMCs-S) & 0.00015 & 0.00010 & 0.000075 & 0.000050 & 0.000038 & 0.000030 \\
$R_{L}$ (OMCs-H) & 0.0015 & 0.00075 & 0.00040 & 0.00030 & 0.000200 & 0.00020 \\
\hline
\end{tabular}

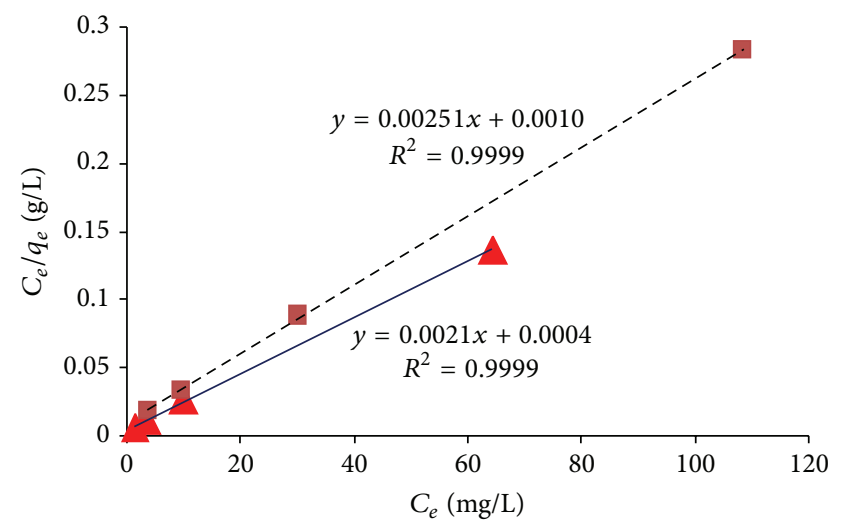

$\Delta$ OMC-H

- OMC-S

Figure 7: Langmuir plot for the adsorption of MB onto the OMCs$\mathrm{H}$ and $\mathrm{OMCs}-\mathrm{S}$.

\section{7. $M B$ Adsorption Kinetics}

3.7.1. Pseudo-First-Order Equation. The rate constant of adsorption is determined from the pseudo-first-order equation given by Langergren [31]:

$$
\ln \left(q_{e}-q_{t}\right)=\ln q_{e}-k_{1} t
$$

where $q_{e}$ and $q_{t}$ are the amounts of MB adsorbed $\left(\mathrm{mg} \cdot \mathrm{g}^{-1}\right)$ at equilibrium and at time $t$, respectively, and $k_{1}$ is the rate adsorption constant.

Figure 8 presents plots of $\ln \left(q_{e}-q_{t}\right)$ versus time $t$ for different $\mathrm{MB}$ concentrations. Values of $k_{1}$ were calculated from
TABLE 5: Rate adsorption constants and MB adsorption capacities calculated according to pseudo-first-order equation of OMCs-S and OMCs-H.

\begin{tabular}{lcccc}
\hline$C_{o}(\mathrm{mg} / \mathrm{L})$ & $R^{2}$ & $k_{1}\left(\mathrm{~h}^{-1}\right)$ & $q_{e, \exp }(\mathrm{mg} / \mathrm{g})$ & $q_{e, \mathrm{cal}}(\mathrm{mg} / \mathrm{g})$ \\
\hline \multicolumn{5}{c}{ OMCs-S } \\
100 & 0.0791 & 0.558 & 166.56 & 0.040 \\
150 & 0.9777 & 1.389 & 249.84 & 3.890 \\
200 & 0.9492 & 0.689 & 332.58 & 89.828 \\
\hline \multicolumn{5}{c}{ OMCs-H } \\
100 & 0.0791 & 0.558 & 197.29 \\
150 & 0.9777 & 1.389 & 292.94 & 0.1579 \\
200 & 0.9492 & 0.689 & 397.94 & 19.222 \\
\hline
\end{tabular}

$q_{e, \text { exp }}: q_{e}$ experimental.

$q_{e, \text { cal }}: q_{e}$ calculated.

the plots of $\ln \left(q_{e}-q_{t}\right)$ versus $t$ for different concentrations of MB on OMCs samples and given in Table 5.

As observed in Table 5, the low value of $R^{2}$ and large difference in $q_{e \text { exp }}$ experimental and $q_{e \text {,cal }}$ calculated values indicate that the MB adsorption on OMCs does not obey the pseudo-first-order equation.

3.7.2. Pseudo-Second-Order Equation. On the other hand, a pseudo-second-order equation based on equilibrium adsorption [32] is expressed as

$$
\frac{t}{q_{t}}=\frac{1}{k_{2} q_{e}^{2}}+\frac{1}{q_{t}} t,
$$

where $k_{2}(\mathrm{~g} / \mathrm{mg} \cdot \mathrm{min})$ is the rates constant of pseudosecond-order adsorption. If pseudo-second-order kinetics is 


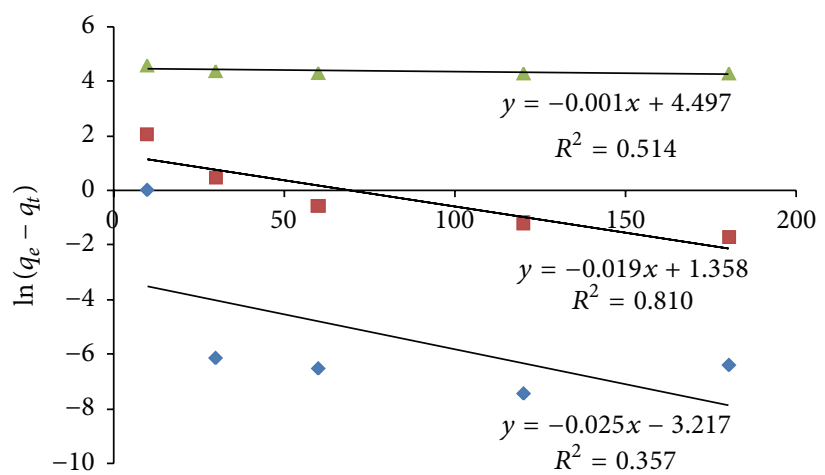

Time (min)

$$
\begin{array}{r}
\quad 100 \mathrm{mg} / \mathrm{L} \\
\text { - } 150 \mathrm{mg} / \mathrm{L} \\
\Delta 200 \mathrm{mg} / \mathrm{L}
\end{array}
$$

(a)

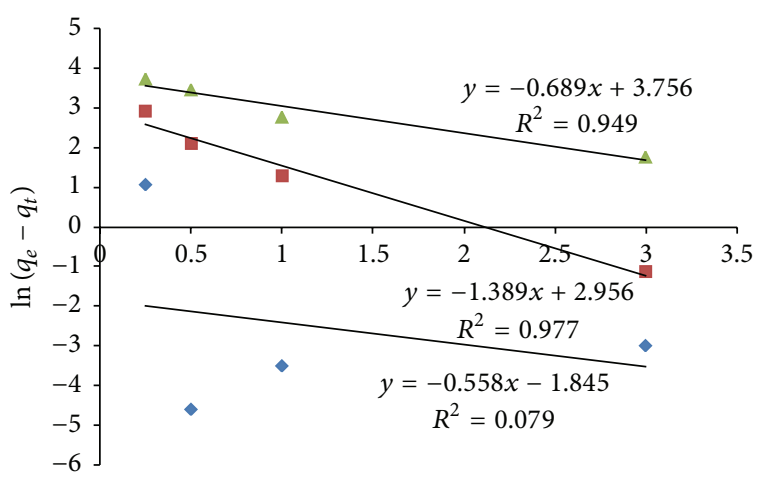

Time (h)

$$
\begin{aligned}
& 100 \mathrm{mg} / \mathrm{L} \\
& 150 \mathrm{mg} / \mathrm{L} \\
& \Delta 200 \mathrm{mg} / \mathrm{L}
\end{aligned}
$$

(b)

Figure 8: Plots of $\ln \left(q_{e}-q_{t}\right)$ versus time $t$ for different MB concentrations on OMCs-S (a) and OMCs-H (b).

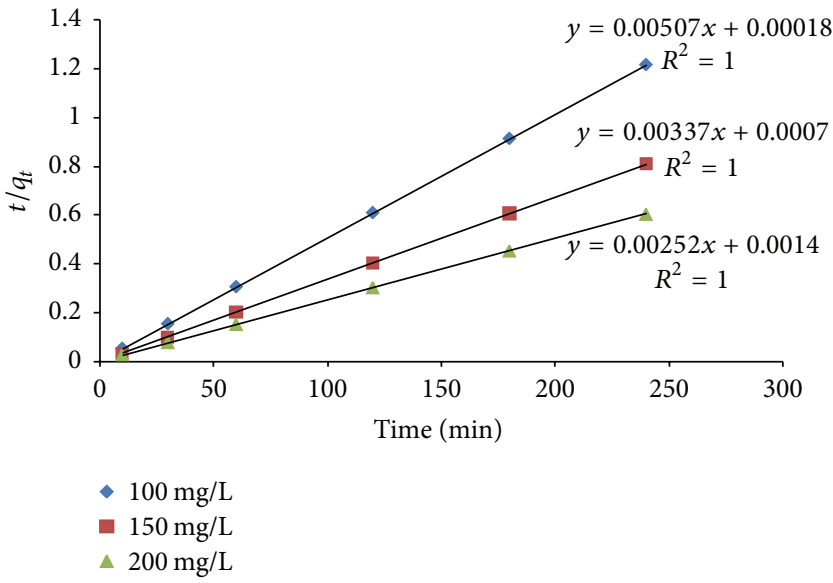

(a)

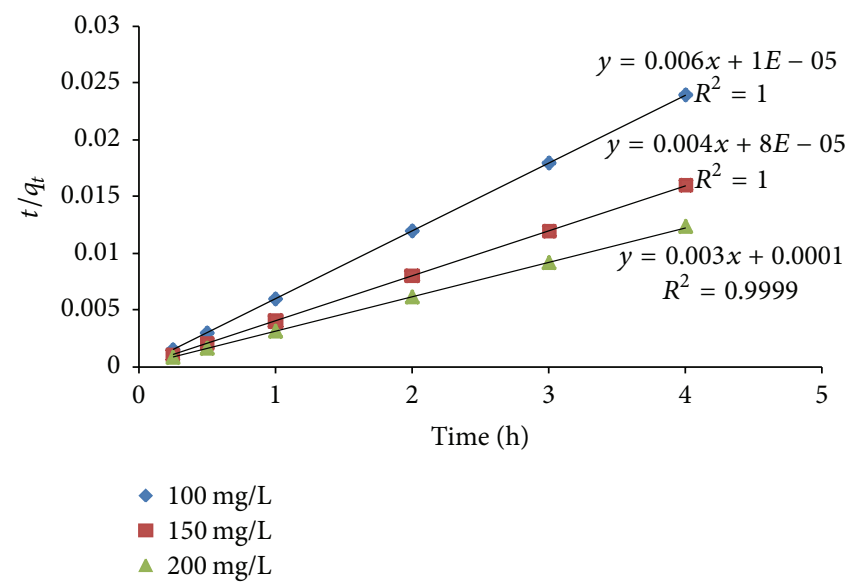

(b)

FIGURE 9: Linear plots of $t / q_{t}$ versus time $t$ for different MB concentrations of OMCs-S (a) and OMCs-H (b).

applicable, the plot of $t / q_{t}$ versus $t$ should show a linear relationship. There is no need to know any parameter beforehand and $q_{e}$ and $k_{2}$ can be determined from the slope and intercept of the plot. Also, this procedure is more likely to predict the behavior over the whole range of adsorption. The linear plots of $t / q_{t}$ versus $t$ are presented in Figure 9 .

Correlation coefficients, $q_{e, \text { exp }}$ experimental and $q_{e, \text { cal }}$ calculated values according to the pseudo-second-order kinetic equation, are shown in Table 6 . As noted in Table 6, the high $R^{2}$ values of $0.9999-1$ as well as the coincidence between $q_{e, \exp }$ experimental and $q_{e, \text { cal }}$ calculated values can confirm that the $\mathrm{MB}$ adsorption in aqueous solution obeys the pseudosecond-order kinetic equation.

\section{Conclusion}

Ordered mesoporous carbons were successfully synthesized by using hard template and soft template methods. From
TABLE 6: Rate adsorption constants and MB adsorption capacities calculated according to pseudo-second-order equation of OMCs- $\mathrm{H}$ and OMCs-S.

\begin{tabular}{lcccc}
\hline$C_{o}(\mathrm{mg} / \mathrm{L})$ & $R^{2}$ & $k_{2}(\mathrm{~g} / \mathrm{mg} \cdot \mathrm{h})$ & $q_{e, \exp }(\mathrm{mg} / \mathrm{g})$ & $q_{e, \text { cal }}(\mathrm{mg} / \mathrm{g})$ \\
\hline \multicolumn{5}{c}{ OMCs-H } \\
100 & 1 & 3.599 & 166.56 & 166.67 \\
150 & 1 & 0.2 & 249.84 & 250 \\
200 & 1 & 0.09 & 332.58 & 333.33 \\
\hline \multicolumn{5}{c}{ OMCs-S } \\
100 & 1 & 3.599 & 197.29 & 197.23 \\
150 & 1 & 0.2 & 292.94 & 296.73 \\
200 & 0.9999 & 0.09 & 397.94 & 396.82 \\
\hline
\end{tabular}

XRD, TEM, and $\mathrm{N}_{2}$ adsorption-desorption (BET) results, it is revealed that the obtained OMCs-S sample had higher surface area $\left(1693 \mathrm{~m}^{2} / \mathrm{g}\right)$ and pore volume $\left(2.374 \mathrm{~cm}^{3} / \mathrm{g}\right)$ 
as compared to those of OMCs-H sample $\left(1041 \mathrm{~m}^{2} / \mathrm{g}\right.$ and $\left.1.237 \mathrm{~cm}^{3} / \mathrm{g}\right)$. At $\mathrm{pH}$ of 7-8, $\mathrm{MB}$ adsorption capacity reached $q_{m}$ of $476 \mathrm{mg} \cdot \mathrm{g}^{-1}$ for OMCs-S and $398 \mathrm{mg} \cdot \mathrm{g}^{-1}$ for OMCs-H, respectively. This opens high application potential of OMCs materials as novel and efficient adsorbents for dye removal from aqueous solution.

\section{Competing Interests}

The authors declare that they have no competing interests.

\section{Acknowledgments}

The authors thank the National Foundation for Science and Technology Development of Vietnam (NAFOSTED) (Grant no. 104.03-2012.34) for financial support.

\section{References}

[1] D. Barrera, M. Dávila, V. Cornette, J. C. A. De Oliveira, R. H. López, and K. Sapag, "Pore size distribution of ordered nanostructured carbon CMK-3 by means of experimental techniques and Monte Carlo simulations," Microporous and Mesoporous Materials, vol. 180, pp. 71-78, 2013.

[2] Y. Gogotsi, Carbon Nanomaterials, CRC Press LLC, Boca Raton, Fla, USA, 2006.

[3] Y. Xia, Z. Yang, and R. Mokaya, Templated Porous Carbon Materials: Recent Developments, John Wiley \& Sons, New York, NY, USA, 2011.

[4] A. Linares-Solano and D. Cazorla-Amoros, Adsorption on Activated Carbon Fibers, Elsevier, New York, NY, USA, 2008.

[5] H. Nishihara and T. Kyotani, "Templated nanocarbons for energy storage," Advanced Materials, vol. 24, no. 33, pp. 44734498, 2012.

[6] F. Schüth, K. S. W. Sing, and J. Weitkamp, Handbook of Porous Solids, vol. 3, Wiley-VCH Verlag GmbH \& Co. KGaA, Berlin, Germany, 2002.

[7] A. Taguchi and F. Schüth, "Ordered mesoporous materials in catalysis," Microporous and Mesoporous Materials, vol. 77, no. 1, pp. 1-45, 2004.

[8] R. Schloegl, Handbook of Heterogeneous Catalysis, Wiley-VCH, Weinheim, Germany, 2008.

[9] G. Hasegawa, K. Kanamori, T. Kiyomura, H. Kurata, T. Abe, and K. Nakanishi, "Hierarchically porous carbon monoliths comprising ordered mesoporous nanorod assemblies for highvoltage aqueous supercapacitors," Chemistry of Materials, vol. 28, no. 11, pp. 3944-3950, 2016.

[10] J. Chen, F. Cao, S. Chen, M. Ni, X. Gao, and K. Cen, "Adsorption kinetics of NO on Ordered Mesoporous Carbon (OMC) and cerium-containing OMC (Ce-OMC)," Applied Surface Science, vol. 317, pp. 26-34, 2014.

[11] Y. Li, B. Yuan, J. Fu, S. Deng, and X. Lu, "Adsorption of alkaloids on ordered mesoporous carbon," Journal of Colloid and Interface Science, vol. 408, no. 1, pp. 181-190, 2013.

[12] F. Cao, J. Chen, M. Ni et al., "Adsorption of NO on ordered mesoporous carbon and its improvement by cerium," RSC Advances, vol. 4, no. 31, pp. 16281-16289, 2014.

[13] M. Ghaedi, A. Shokrollahi, H. Hossainian, and S. Nasiri Kokhdan, "Comparison of activated carbon and multiwalled carbon nanotubes for efficient removal of eriochrome cyanine $\mathrm{R}$ (ECR): kinetic, isotherm, and thermodynamic study of the removal process," Journal of Chemical \& Engineering Data, vol. 56, no. 7, pp. 3227-3235, 2011.

[14] L. Eskandarian, M. Arami, and E. Pajootan, "Evaluation of adsorption characteristics of multiwalled carbon nanotubes modified by a poly(propylene imine) dendrimer in single and multiple dye solutions: isotherms, kinetics, and thermodynamics," Journal of Chemical and Engineering Data, vol. 59, no. 2, pp. 444-454, 2014.

[15] W. Libbrecht, K. Vandaele, K. De Buysser et al., "Tuning the pore geometry of ordered mesoporous carbons for enhanced adsorption of bisphenol-A," Materials, vol. 8, no. 4, pp. 16521665, 2015.

[16] J. Hu, M. Noked, E. Gillette et al., "Dual-template synthesis of ordered mesoporous carbon $/ \mathrm{Fe}_{2} \mathrm{O}_{3}$ nanowires: high porosity and structural stability for supercapacitors," Journal of Materials Chemistry A, vol. 3, no. 43, pp. 21501-21510, 2015.

[17] D. Saha, R. Zacharia, and A. K. Naskar, "Soft-templated mesoporous carbons: chemistry and structural characteristics," in Polymer Precursor-Derived Carbon, chapter 4, pp. 61-83, American Chemical Society, 2014.

[18] X. Yuan, S.-P. Zhuo, W. Xing et al., "Aqueous dye adsorption on ordered mesoporous carbons," Journal of Colloid and Interface Science, vol. 310, no. 1, pp. 83-89, 2007.

[19] X. Peng, D. Huang, T. Odoom-Wubah, D. Fu, J. Huang, and Q. Qin, "Adsorption of anionic and cationic dyes on ferromagnetic ordered mesoporous carbon from aqueous solution: equilibrium, thermodynamic and kinetics," Journal of Colloid and Interface Science, vol. 430, pp. 272-282, 2014.

[20] J. M. Gómez, J. Galán, A. Rodríguez, and G. M. Walker, "Dye adsorption onto mesoporous materials: $\mathrm{pH}$ influence, kinetics and equilibrium in buffered and saline media," Journal of Environmental Management, vol. 146, pp. 355-361, 2014.

[21] Z. Sui, Q. Meng, X. Zhang, R. Ma, and B. Cao, "Green synthesis of carbon nanotube-graphene hybrid aerogels and their use as versatile agents for water purification," Journal of Materials Chemistry, vol. 22, no. 18, pp. 8767-8771, 2012.

[22] I. I. Gurten, M. Ozmak, E. Yagmur, and Z. Aktas, "Preparation and characterisation of activated carbon from waste tea using $\mathrm{K}_{2} \mathrm{CO}_{3}$," Biomass and Bioenergy, vol. 37, pp. 73-81, 2012.

[23] E. N. El Qada, S. J. Allen, and G. M. Walker, "Adsorption of basic dyes from aqueous solution onto activated carbons," Chemical Engineering Journal, vol. 135, no. 3, pp. 174-184, 2008.

[24] O. Gulnaz, A. Kaya, F. Matyar, and B. Arikan, "Sorption of basic dyes from aqueous solution by activated sludge," Journal of Hazardous Materials, vol. 108, no. 3, pp. 183-188, 2004.

[25] G. McKay, J. F. Porter, and G. R. Prasad, "The removal of dye colours from aqueous solutions by adsorption on low-cost materials," Water, Air, and Soil Pollution, vol. 114, no. 3, pp. 423438, 1999.

[26] C. Nie, L. Huang, D. Zhao, and Q. Li, "08-P-13-Stability of mesoporous material SBA-15 and its benefit in catalytic performance," Studies in Surface Science and Catalysis, vol. 135, p. 286, 2001.

[27] H. Hashemipour Rafsanjani, H. Kamandari, and H. Najjarzadeh, "Study on pore and surface development of activated carbon produced from Iranian coal in a rotary kiln reactor," Iranian Journal of Chemical Engineering (IJChE), vol. 10, no. 3, pp. 27-38, 2013. 
[28] S. C. Kim and I. K. Hong, "Pore development of the activated carbon prepared by steam activation process," Journal of Industrial and Engineering Chemistry, vol. 4, no. 3, pp. 177-184, 1998.

[29] Y. Li, F. Liu, B. Xia et al., "Removal of copper from aqueous solution by carbon nanotube/calcium alginate composites," Journal of Hazardous Materials, vol. 177, no. 1-3, pp. 876-880, 2010.

[30] X. W. Zhao, Q. Jia, N. Z. Song, W. H. Zhou, and Y. S. Li, "Adsorption of $\mathrm{Pb}$ (II) from an aqueous solution by titanium dioxide/carbon nanotube nanocomposites: kinetics, thermodynamics, and isotherms," Journal of Chemical \& Engineering Data, vol. 55, no. 10, pp. 4428-4433, 2010.

[31] S. Langergren, "Zurtheorie der sogenannten adsorption gelöster stoffe," Kungliga Svenska Vetenskapsakademiens Handlingar, vol. 24, no. 4, pp. 1-39, 1898.

[32] Y. S. Ho and G. McKay, "Sorption of dye from aqueous solution by peat," Chemical Engineering Journal, vol. 70, no. 2, pp. 115124, 1998. 

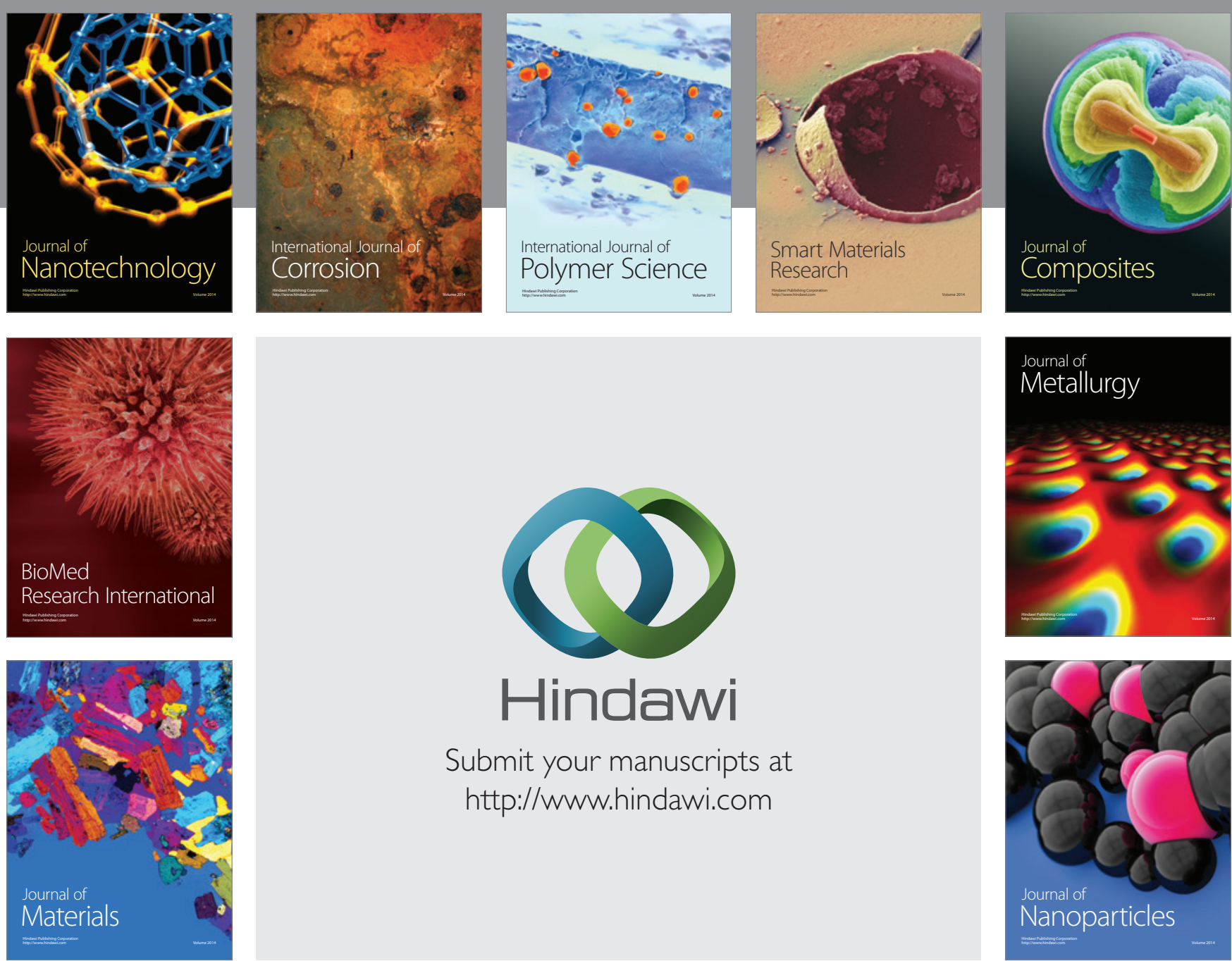

\section{Hindawi}

Submit your manuscripts at

http://www.hindawi.com

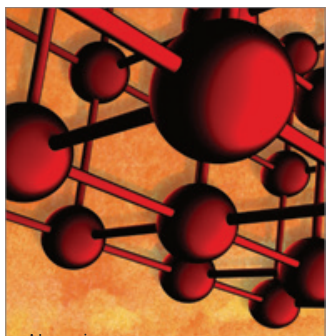

Materials Science and Engineering
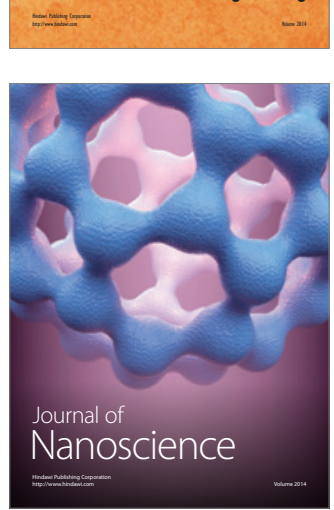
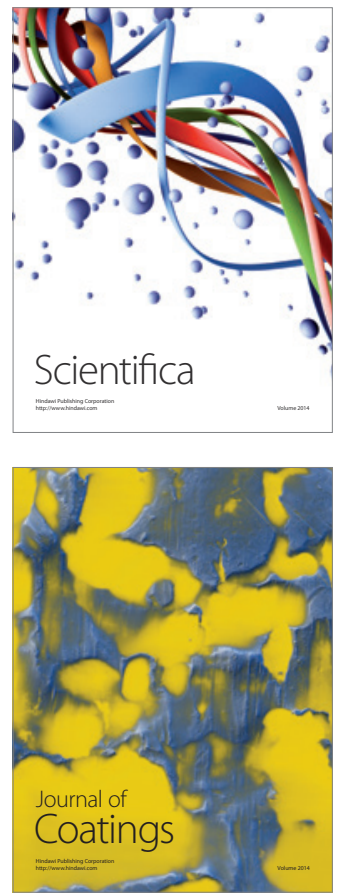
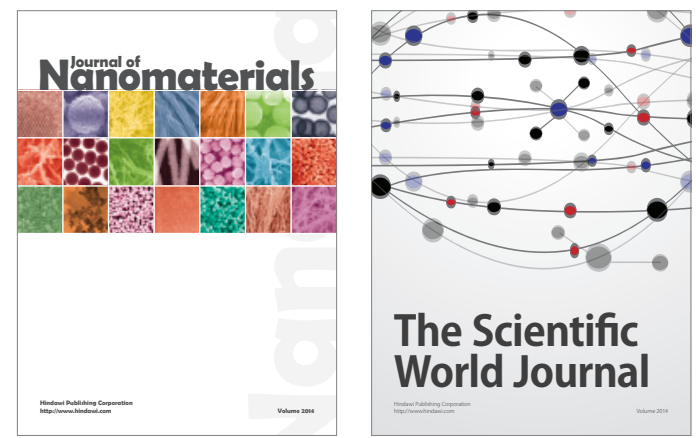

The Scientific World Journal
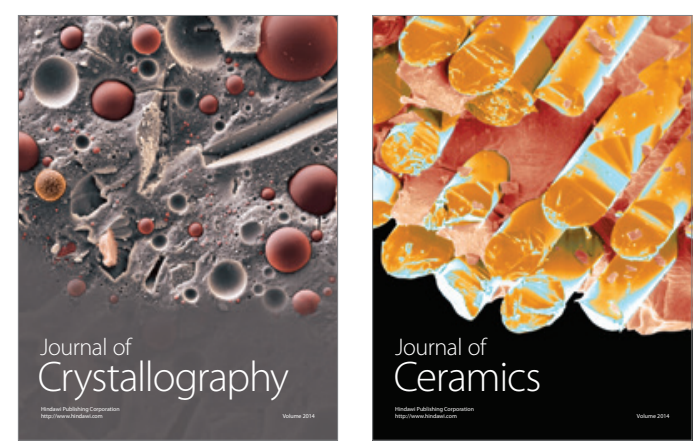
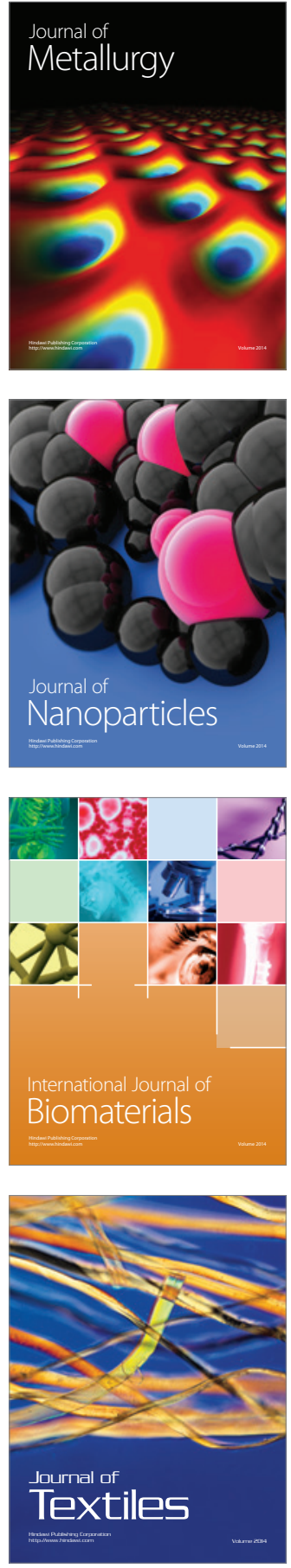